\title{
BMJ Open Evaluation of a heat warning system in Adelaide, South Australia, using case-series analysis
}

\author{
Monika Nitschke, ${ }^{1,2}$ Graeme Tucker, ${ }^{3,4}$ Alana Hansen, ${ }^{2}$ Susan Williams, ${ }^{2}$ \\ Ying Zhang, ${ }^{5}$ Peng $\mathrm{Bi}^{2}$
}

To cite: Nitschke M, Tucker G, Hansen A, et al. Evaluation of a heat warning system in Adelaide, South Australia, using case-series analysis. BMJ Open 2016;6: e012125. doi:10.1136/ bmjopen-2016-012125

- Prepublication history and additional material is available. To view please visit the journal (http://dx.doi.org/ 10.1136/bmjopen-2016012125).

Received 4 April 2016 Revised 17 May 2016 Accepted 3 June 2016

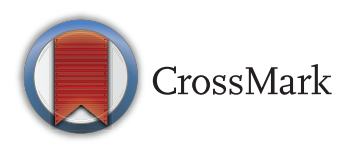

${ }^{1}$ Public Health Services, Department for Health and Ageing, Adelaide,

South Australia, Australia

${ }^{2}$ School of Public Health, University of Adelaide, Adelaide, South Australia, Australia

${ }^{3}$ Epidemiology, Department for Health and Ageing, Adelaide, South Australia, Australia

${ }^{4}$ School of Medicine, University of Adelaide, Adelaide, South Australia, Australia

${ }^{5}$ International Public Health, University of Sydney, Sydney, New South Wales, Australia

Correspondence to Dr Monika Nitschke; monika.nitschke@health. sa.gov.au

\section{ABSTRACT}

Background: Heatwave warning systems aim to assist in reducing health effects during extreme heat. Evaluations of such systems have been limited. This study explored the effect of a heatwave warning programme on morbidity and mortality in Adelaide, South Australia, by comparing extreme events in 2009 and 2014, the latter with exposure to the preventive programme.

Methods: The health outcomes during the two heatwaves were compared using the incidence rate ratios (IRRs) of daily ambulance call-outs, emergency presentations and mortality data during the heatwaves compared with non-heatwave periods during the warm seasons. Excess or reduced numbers of cases were calculated and the differences in cases between the two heatwaves were estimated.

Results: IRRs for total ambulance call-outs and emergency presentations were lower during the 2014 heatwaves compared with the 2009 event. The estimated differences in health-specific outcomes between 2009 and 2014 were statistically significant with 207 (59\%) for cardiac-related call-outs, 134 $(30 \%)$ for renal and $145(56 \%)$ for heat-related emergency presentations. Mortality was not reduced in 2014. There were an estimated 34.5 excess deaths in 2009 and 38.2 in 2014.

Conclusions: Morbidity outcomes were reduced significantly during the 2014 event. The fact that cardiac, renal and heat-related diagnoses were significantly reduced is likely to be associated with the intervention in 2014, which comprised a public warning through media and intense preventive measures directed to individual populations at risk. Further analysis of risk factors of mortality during heatwaves should be explored.

\section{INTRODUCTION}

Health effects during extreme heat should be largely preventable. However, during recent heat events worldwide and in Australia, significant increases in morbidity and mortality have been evident. A systematic analysis of health effects during heatwaves (3 or more days of

\section{Strengths and limitations of this study}

- Heatwave warning systems based on defined temperature triggers and adaptive public health measures have been implemented in many cities, but the evaluation of the effectiveness of these systems is limited to mortality.

- This study used morbidity and mortality data from two extreme heatwave periods, before and after the introduction of a heatwave warning system in Adelaide, South Australia, to compare the impact.

- There are limitations in conclusively evaluating the effects of a population-based heat-health intervention. It could be argued that improvements in health outcomes could be due to adaptation to heat or that it is difficult to compare heatwave events.

- Significant morbidity reductions were observed, suggesting that preventive measures contributed to this success. As this was not the case for mortality, further efforts have to be made to explore the reduction of risk factors for mortality during heatwaves.

- Evaluation of interventions is an iterative process and should be used continuously alongside fine tuning of the intervention measures using evidence-based research.

maximum temperature $\geq 35^{\circ} \mathrm{C}$ ) for Adelaide, the capital of South Australia (SA) (19932006), indicated morbidity incidence above what is normally expected during summer periods, but did not show any increases in mortality. ${ }^{1}$ This changed when a record-breaking 13-day heatwave occurred in summer 2009, during which mortality increased by $37 \%$ in the 15-64 age groups together with large increases in renal, ischaemic heart disease and direct heat-related morbidity. ${ }^{2}$

The unparalleled event in summer 2009 evoked the need for a heat warning system (HWS) for metropolitan Adelaide's 1.30 million residents, $76.9 \%$ of the total SA population, considering the predictions of an increased frequency of extreme heatwaves 
under the climate change scenario for SA. An HWS was introduced in November 2009, following the extreme heatwave in January and February 2009. These systems are now in place in many cities of the world.

Several HWSs in the USA were initiated in response to extreme heatwaves. ${ }^{3}{ }^{4}$ Since the 2003 heatwave in Europe, HWSs have been also rolled out for many European cities. ${ }^{5}{ }^{6}$ Only recently, the WHO in conjunction with the World Meteorological Organization (WMO) published a guidance document on the development of HWSs. ${ }^{7}$ The Adelaide HWS addresses most of the pertinent elements presented in the $\mathrm{WHO} / \mathrm{WMO}$ framework, including a definition of the event, an across the government-agreed division of roles and responsibilities to reduce possible health effects among those at risk and a communications strategy to engage with the general population. The process of establishing an HWS in Adelaide has been described in a recent qualitative study outlining the collaborative stakeholder engagement process by the state government. $^{8}$

Another key factor mentioned in the $\mathrm{WHO} / \mathrm{WMO}$ framework is the need to evaluate the success of the health warnings; whether it has offered health protection verified by a reduction of cases of heat-related illnesses compared to what was expected from previous events, or in terms of public recall of information, and whether the warning changed the behaviour of people at risk. ${ }^{7}$ Evaluating heat warning interventions has been the subject of two recent reviews. ${ }^{9} 10$ They concur that the limited intervention studies present indicated positive results. Most of the studies were limited to the evaluation of mortality. Evaluations of impacts were hampered by the fact that subsequent heatwaves had different intensities and durations. ${ }^{10} 11$

In summer 2014, the Adelaide extreme HWS was twice activated within a 1-month period, and when combined, these two heatwave periods resembled in duration and intensity the 2009 heat event. This provided a timely opportunity to compare health outcomes during those events as part of an evaluation of the effectiveness of the heat-health intervention in Adelaide.

\section{METHODS}

The study is of ecological design comparing morbidity and mortality of two extreme heatwaves at the population level.

\section{Health data}

Morbidity and mortality data for metropolitan Adelaide for the warm seasons (October-March) from 1993 to 2014 were obtained from the Department for Health and Ageing. For comparison purposes, the specific health outcome categories chosen for analysis were those that were significantly increased during the 2009 heatwave (hw2009). Ambulance call-out data were obtained from SA Ambulance Service.
The following International Classification of Disease (ICD-10) categories of diseases were selected for emergency department presentations (hospital admissions data were also obtained and the results can be seen in the appendix online): renal (ICD-10 N00-N399) and direct heat related (ICD-10, E86, T67, X30). The predefined categories provided by SA Ambulance Service for call-outs were used. Only total mortality data were used as cause-specific data for 2014 were unavailable.

\section{Heat-health interventions}

Table 1 summarises the elements of Adelaide's short-term interventions during extreme heat warning episodes.

The HWS has an all-government approach with the State Emergency Service (SES) as the 'Hazard Leader'. ${ }^{12}$ An HWS is triggered during extreme heat events in conjunction with the Bureau of Meteorology (BOM) when an average daily temperature (ADT) of $\geq 32^{\circ} \mathrm{C}$ is forecast for three or more days (average of daily maximum and minimum=ADT; eg, $40^{\circ} \mathrm{C}+24^{\circ} \mathrm{C} / 2=32$ ). This temperature threshold is based on retrospective analysis of health and temperature data. ${ }^{13}{ }^{14}$ On reaching the threshold, the government activates heat-related interventions to the specific needs of vulnerable populations. For example, all people who access one or more social services are monitored regarding their well-being. The general public is warned, informed and educated through media announcements.

The Australian Red Cross operates an important free service in collaboration with the state government, specifically directed to people at risk. Those who have been registered are contacted on a daily basis during the warning period. Carers, doctors, friends and family members can enrol a person in this system based on a vulnerability assessment tool. ${ }^{15}$

Preseason work is invested into reassessing extreme heat plans and intervention measures based on ongoing risk factors research. ${ }^{16-18}$

\section{Temperature data}

Temperature data were obtained from a BOM weather station which is representative of the metropolitan area of Adelaide.

The definition ( 3 or more days of $\geq 35^{\circ} \mathrm{C}$ ) for heatwave impact assessments in Adelaide was used to compare the health impacts during the 2014 heatwaves with those in 2009. ${ }^{2}$ The hw2009 (26 January-7 February) lasted 13 days with an average maximum temperature of $41^{\circ} \mathrm{C}$ and an average minimum temperature of $26.1^{\circ} \mathrm{C}$. The 2014 heatwave (hw2014) is a composite of two heatwaves with only 9 days in between (12 January-17 January and 27 January-2 February 2014). Each of the events (hw2009 and hw2014) included 1 day below $35^{\circ} \mathrm{C}$. The average maximum temperature during the first component of the hw2014 was $42.2^{\circ} \mathrm{C}$ and the minimum was $24.8^{\circ} \mathrm{C}$; for the second composite period, it was $39.4^{\circ} \mathrm{C}$ and $21.5^{\circ} \mathrm{C}$, respectively. During both hw2014 periods, extreme heat warnings were triggered. Table 1 in the 
Table 1 Extreme heat warning in Adelaide, South Australia: description of the programme and interventions

\begin{tabular}{|c|c|c|c|}
\hline Lead agencies & Triggers/threshold & Interventions & \\
\hline $\begin{array}{l}\text { SA State Emergency Service } \\
\text { (SES) is advised by Bureau } \\
\text { of Meteorology (BOM). SES } \\
\text { informs other agencies with } \\
\text { one lead day }\end{array}$ & $\begin{array}{l}\text { 3-day rolling forecast of } \\
\text { average daily (minimum and } \\
\text { maximum temperatures } \\
\text { divided by two) temperatures } \\
\text { (ADTs) } \\
\text { Threshold for an extreme } \\
\text { heat warning is reached } \\
\text { when ADT is } 32^{\circ} \mathrm{C} \text { or above } \\
\text { (eg, } 40^{\circ} \mathrm{C} \text { daytime and } 24^{\circ} \mathrm{C} \\
\text { night-time) }\end{array}$ & $\begin{array}{l}\text { Before/start of summer } \\
\text { and ongoing: } \\
\text { General heat health } \\
\text { advice before summer. } \\
\text { Heat plan review of all } \\
\text { relevant government } \\
\text { and non-government } \\
\text { agencies. } \\
\text { Meeting of all agencies } \\
\text { before the summer } \\
\text { season to discuss } \\
\text { coordination issues. } \\
\text { Collaborative research } \\
\text { agenda. }\end{array}$ & $\begin{array}{l}\text { During the alert: } \\
\text { Activation of specific and } \\
\text { coordinated extreme heat } \\
\text { plans (local government, state } \\
\text { government and } \\
\text { non-government), see } \\
\text { examples: } \\
\text { - Public alerts and advice } \\
\text { through media. } \\
\text { - Continuous review of } \\
\text { emergency, ambulance } \\
\text { and other clinical response } \\
\text { capabilities in the health } \\
\text { sector. } \\
\text { - Australian Red Cross } \\
\text { provision of free support } \\
\text { calls to registered } \\
\text { vulnerable people. }\end{array}$ \\
\hline
\end{tabular}

$\mathrm{ADT}$, average daily temperature.

online appendix shows the temperature constellation for the 2009 and 2014 heatwaves in more details highlighting the days during which an extreme heat warning was triggered (based on $\mathrm{ADT}=32^{\circ} \mathrm{C}$ forecast by $\mathrm{BOM}$ ).

\section{Statistics}

To compare health impacts, a case-series analysis was used. ${ }^{19}$ Average daily rates of adverse health outcomes during the defined heatwaves were compared with nonheatwave periods during the respective warm seasons. The rate ratios of incidences of health outcomes during 'case' and 'control' periods were expressed as incidence rate ratios (IRRs).

The analysis was conducted within years, therefore implicitly adjusting for long-term trends for the years 1993-2014, which provides more accurate SEs when data are overdispersed. ${ }^{20}$ To calculate the IRR, Poisson regression models were fitted using the statistical software package Stata V.13 (StataCorp. Stata Statistical Software: Release 13.1. College Station, TX: StataCorp LP, 2013.). Each model was tested for fit, and negative binomial regression models were used to allow for overdispersion if required. To assess the impact of the intervention, the statistical significance of the difference between the 2009 and 2014 IRRs was estimated using the postestimation command 'lincom' in Stata. Furthermore, expected cases were calculated from the total of the observed cases $(\mathrm{N})$ during the respective heatwave period divided by the IRR of the relevant health outcome. Excess (or reduced) cases were obtained by subtracting expected from observed cases $[\mathrm{N}-(\mathrm{N} / \mathrm{IRR})]$. The difference between excess cases in 2009 and 2014 provided an indicator of effectiveness of the intervention. SEs were manipulated using the formulae provided in
Hansen $e t a l^{21}$ to produce a $95 \%$ CI for the estimates of the excess/reduction and the difference in cases between the 2009 and 2014 events (see online supplementary appendix for formulae).

\section{RESULTS}

Table 2 provides summary statistics for daily average health outcomes during the two comparison heatwave and non-heatwave periods in 2009 and 2014. Ambulance call-outs during the hw2009 and hw2014 were higher compared with their respective non-heatwave periods. Unlike in the hw2009, when average daily hospital and emergency presentations were higher than during the respective non-heatwave periods, this was reversed in the hw2014. As in 2009, average mortality was higher during the heatwave compared with the non-heatwave days in 2014.

\section{Ambulance call-outs}

Table 3 shows the IRRs for ambulance call-outs during heatwaves compared with non-heatwave periods in 2009 and 2014. In 2009, the incidence of total ambulance call-outs increased by $16 \%$ over non-heatwaves in the warm season. Compared with hw2009, total call-outs were decreased during hw2014, with the 2014 point estimate indicating a non-significant $5 \%$ increase over non-heatwave periods. Reductions compared to hw2009 were also evident across all age groups.

Total and age-related cardiac-related call-outs in 2014 showed a protective effect during the heatwaves compared with the non-heatwave periods. In 2009, the reverse occurred. 
Table 2 Descriptive statistics for total daily health outcomes for summer 2008/2009 and 2013/2014 (October-March), for the two defined heatwave (hw) (13 days) and non-heat wave periods (169 days): minimum, maximum, mean and SD of daily incidences of ambulance call-outs, hospital admissions, emergency presentations and mortality

\begin{tabular}{|c|c|c|c|c|}
\hline Description & Minimum & Maximum & Mean & SD \\
\hline \multicolumn{5}{|l|}{ Ambulance call-outs } \\
\hline hw 2009: 13 days & 243 & 361 & 291.1 & 36.1 \\
\hline Non-hw periods 2009: 169 days & 187 & 301 & 249.5 & 20.1 \\
\hline hw 2014: 13 days & 306 & 392 & 342.9 & 25.4 \\
\hline Non-hw periods 2014: 169 days & 258 & 391 & 326.4 & 25.0 \\
\hline \multicolumn{5}{|l|}{ Hospital admissions } \\
\hline hw 2009 & 460 & 1742 & 1322.9 & 506.4 \\
\hline Non-hw periods 2009 & 271 & 1798 & 1231.5 & 523.4 \\
\hline hw 2014 & 399 & 1713 & 1300.0 & 528.8 \\
\hline Non-hw periods 2014 & 334 & 1972 & 1311.7 & 553.9 \\
\hline \multicolumn{5}{|l|}{ Emergency department presentations } \\
\hline hw 2009 & 905 & 1065 & 994.5 & 54.3 \\
\hline Non-hw periods 2009 & 802 & 1122 & 971.5 & 59.0 \\
\hline hw 2014 & 918 & 1139 & 999.9 & 55.7 \\
\hline Non-hw periods 2014 & 915 & 1209 & 1034.3 & 66.4 \\
\hline \multicolumn{5}{|l|}{ Mortality } \\
\hline hw 2009 & 15 & 44 & 28.6 & 9.4 \\
\hline Non-hw periods 2009 & 14 & 41 & 26.1 & 5.6 \\
\hline hw 2014 & 21 & 34 & 28.0 & 4.1 \\
\hline Non-hw periods 2014 & 15 & 38 & 25.3 & 4.7 \\
\hline
\end{tabular}

\section{Comparing 2014 and 2009}

Comparing IRRs indicated significant reductions in all-age total and cardiac-related call-outs occurring in 2014. Age-specific differences were manifested in the $75+$ age group for total call-outs and for cardiac call-outs in all adult age groups.

There were 220 excess ambulance call-outs estimated during the hw2014 compared with 518 in the hw2009 (table 3). A total of 59 excess cardiac-related call-outs were estimated for the hw2009; in 2014, a significant reduction of 148 cardiac-related call-outs was assessed. Based on these estimates, there were $297(9 \%)$ fewer total call-outs and $207(59 \%)$ fewer cardiac-related call-outs during the hw2014 than the hw2009 outcomes.

\section{Emergency presentations}

Table 4 presents the IRRs of the emergency presentations for the 2009 and 2014 heatwaves. Total emergency presentations were increased during hw2009; however, in hw2014, a significant 3\% decrease was observed when compared with non-heatwave periods. This inverse risk was predominantly observed in the younger age groups. Comparison of the hw2009 and hw2014 IRRs indicated that the reduction was significant for emergency presentations in the $75+$ age group only. Renal and heat-related presentations were significantly increased within several age groups during hw2009. During the hw2014, renal presentations were very similar to the non-heatwave periods indicated by IRRs near one. Heat-related IRRs were reduced by more than half, but still indicated significant increases over non-heatwave periods.

\section{Comparing 2009 and 2014}

When compared, renal and heat-related IRRs were statistically significantly reduced for total presentations and for almost all age groups.

Total emergency presentations were reduced by 440 compared with non-heatwave periods (table 4) in 2014, while in 2009, an excess of 302 cases were estimated. On both occasions, the CIs were wide and the results were non-significant. The difference between 2009 and 2014 presentations indicated a non-significant reduction of 742 cases.

There were 125 excess renal presentations estimated during hw2009 and a reduction of 8.7 cases in 2014 . The difference between 2009 and 2014 was statistically significant with an estimated $134(30 \%)$ fewer renal cases than expected.

The excess in heat-related presentations during hw2014 was estimated to be 160 cases, approximately half of the excess 304 cases in 2009. The difference between the 2009 and 2014 events showed a significant reduction of $145(56 \%)$ heat-related cases compared with expected cases.

\section{Mortality}

When compared with non-heatwave periods, total mortality increased during hw2009 (11\%) and hw2014 $(12 \%)$, with the increase during hw2014 being statistically significant. Table 5 displays the estimates for excess mortality for the 2009 and 2014 events and indicates that the difference between hw2009 (34.5 cases) and hw2014 (38.2 cases) was approximately four extra mortality cases, which was not statistically significant. 


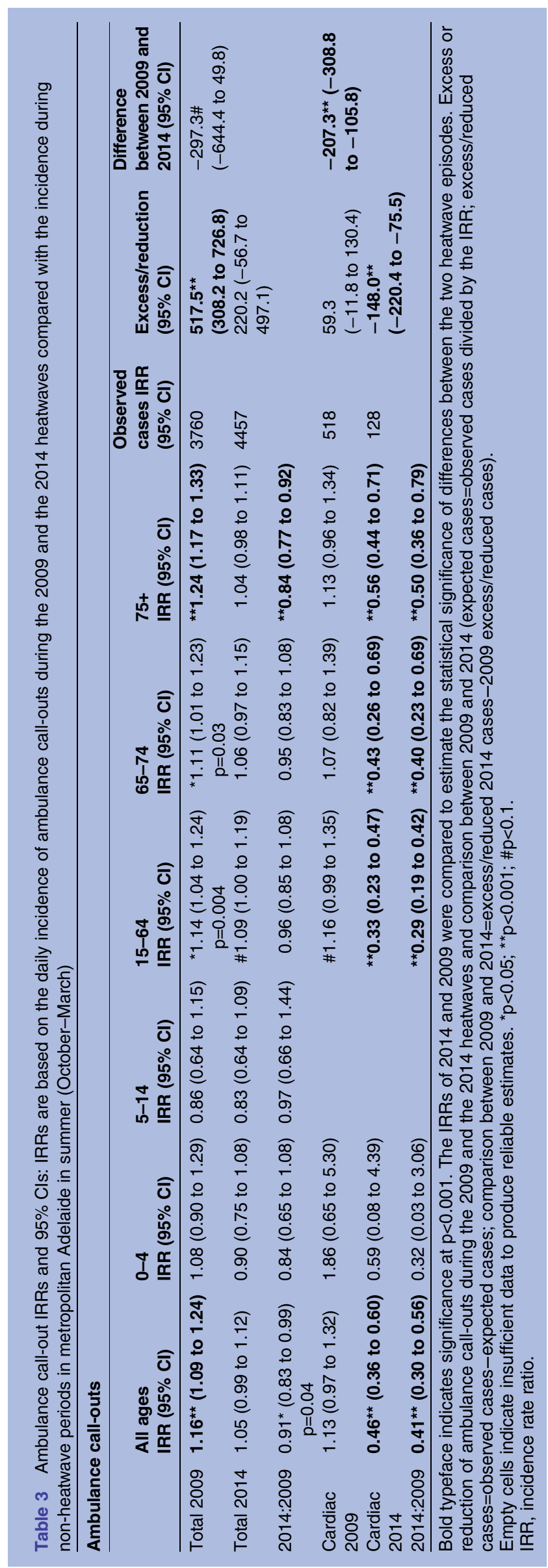

Hospital admissions

The results from the analysis of hospital admissions data showed similar trends to emergency presentations, with a reduced impact on renal and heat-related hospital admissions apparent during hw2014 compared with hw2009. These results are included in the online appendix as table 2.

\section{DISCUSSION}

Quantitative evaluation of the effectiveness of public health interventions for heatwaves can be difficult if comparable weather conditions do not occur thereafter. In summer 2014, extreme heat warnings were pronounced twice in short succession in Adelaide, and the heat intensity and duration closely resembled the single extreme 2009 event. This conjuncture enabled a quantitative assessment of an HWS (the intervention) which was introduced after the hw2009.

There was only one other notable heat event in recent years occurring in March 2008, with 15 consecutive days of $35^{\circ} \mathrm{C}$ and over, but temperatures merely skimmed the $40^{\circ} \mathrm{C}$ mark. The heatwave was therefore not comparable with the 2009 and 2014 events which all included consecutive days well over $40^{\circ} \mathrm{C}$ including high overnight temperatures, a heat-health threshold pattern that is now recognised as being associated with considerable risks in Adelaide's population. ${ }^{2} 1314$

The evaluation of an intervention is an important task considering that intervention measures can be costly. There are various measures of success, including improvement of public awareness, behaviour changes or reduced health outcomes. ${ }^{22}$ The latter was the aim of this evaluation. The cornerstones of the intervention are the threshold-based triggers for activation of the system, the Red Cross welfare checks, extensive media coverage and the roll-out of heat plans into the relevant vulnerable communities. ${ }^{13} 14$

Our analysis indicates that the heatwave event in 2014 was associated with fewer adverse health outcomes than observed during hw2009, including ambulance call-outs, emergency presentations and hospital admissions. As the two heatwave events were comparable in their duration and intensity, our findings suggest that the interventions during hw2014 were effective in minimising the population health impact of this event.

It is possible that post hw2009 adaptation has occurred and people have implemented changes in their households such as the installation of air conditioners, extra shading, heat-related structural changes to the built environment and behaviour changes. Notwithstanding, the large reductions in health outcomes are unlikely to have occurred without the parallel development of the HWS. This is supported by the findings from a recent heat-related representative survey in the older population in SA following introduction of the HWS, which established that $76.4 \%$ of the 499 responders recalled health warnings being issued during extreme heat in 
Table 4 Emergency IRRs and 95\% Cls: IRRs are based on the daily incidence of emergency presentations during the 2009 and the 2014 heatwaves compared with the incidence during non-heatwave periods in metropolitan Adelaide in summer (October-March)

Emergency presentation

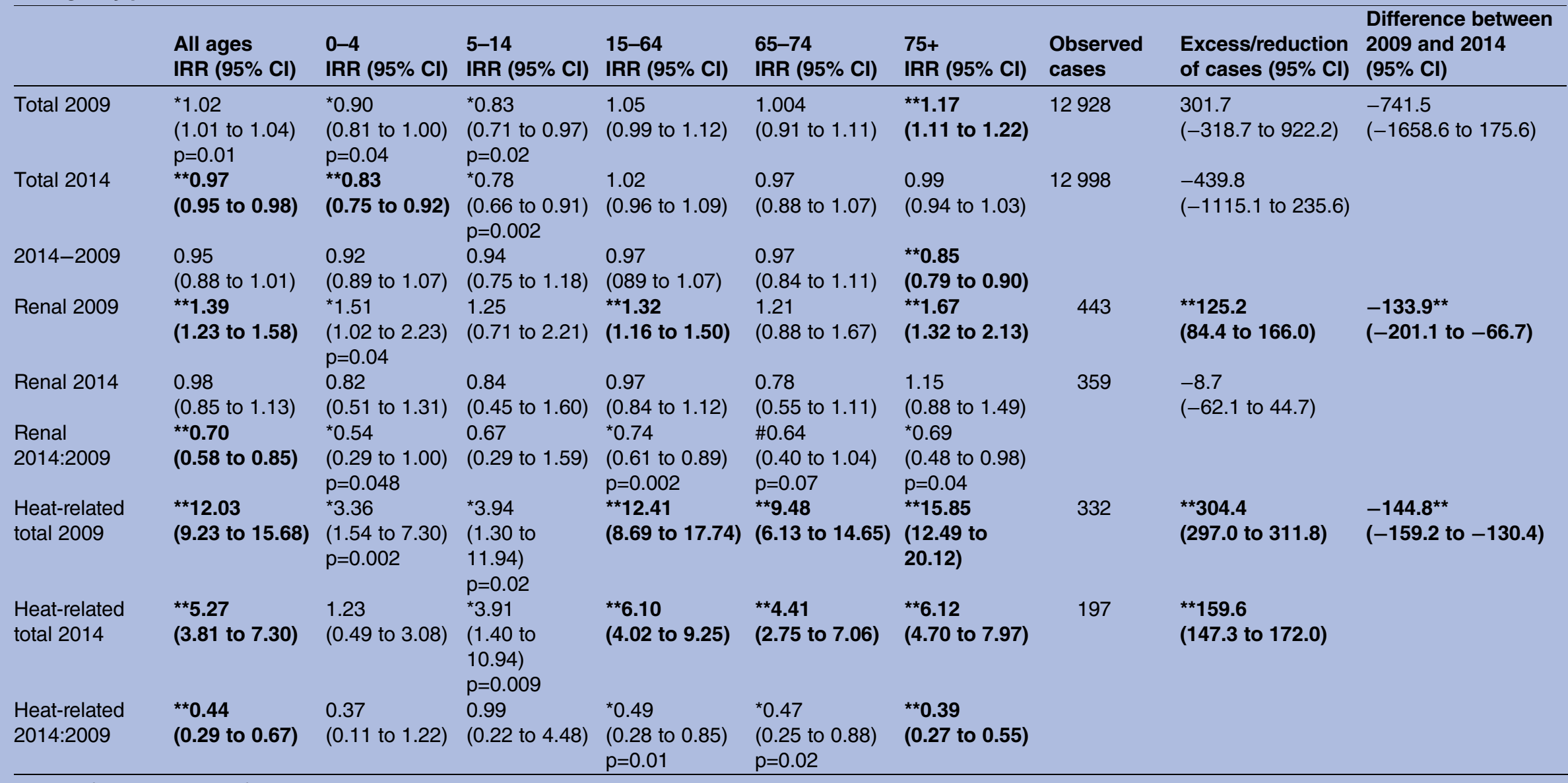

Bold typeface indicates significance at $\mathrm{p}<0.001$

The IRRs of 2014 and 2009 were compared to estimate the statistical significance of differences between the two heatwave episodes. ${ }^{*} p<0.05 ;{ }^{* *} p<0.001 ; \# p<0.1$.

IRR, incidence rate ratio. 
SA. ${ }^{17}$ The two messages that stood out most as being recalled were 'stay hydrated' $(78 \%)$ and 'minimise sun exposure' $(53 \%)$. Also, when asked about change of behaviour due to heat warnings, $44 \%$ of respondents answered positively.

While direct heat-related IRRs were reduced in the hw2014 compared with the hw2009, they were still significantly increased, indicating scope for further prevention measures. An apparent protective effect of heatwaves on renal emergency presentations in 2014 (and hospital related; online supplementary file) is counterintuitive considering our previous renal results and evidence from other studies. ${ }^{23-26}$ It may have been due to people being particularly cautious about maintaining hydration in response to heat warnings but overlooking the importance of fluid intake throughout summer. The messages disseminated during the heat warnings in 2014 focused on personal reduction of heat exposure and the need for adequate hydration. ${ }^{27}$ It is possible that the reductions in renal and heat-related cases may have been due to people changing behaviours as a result of the wide distribution of these messages and the special attention attributed to the at-risk population.

While the results show morbidity reductions in 2014 compared with 2009, the excess mortality remained relatively constant. In 2009, 34.5 excess deaths (11\%) were estimated and $38.2(12 \%)$ in 2014. Compared with other cities, and considering population size, Adelaide has a low excess mortality during extreme heat. In 2009, simultaneously to the Adelaide heatwave, Victoria reported 374 excess deaths $(62 \%$ increase $) .^{28}$ In Chicago in 1995, 700 excess deaths ( $74 \%$ increase on the day with highest excess deaths) were reported, and in the major European heat wave of 2003, >15 000 $(60 \%)$ excess deaths occurred in France alone. ${ }^{29-31}$ The lower excess mortality in Adelaide, especially in comparison with Victoria, may be explained by better adaptation to heat due to more extensive and extreme historical heat experience. A comparison of heathealth behaviours in older people in Victoria and SA after the 2009 event indicated that older people in SA had a higher prevalence of air conditioners and a higher recall of heat-related warning messages compared with their Victorian counterparts. ${ }^{32}$ Nevertheless, an increase of $12 \%$ of mortality is still too high considering that deaths due to high temperatures should, in theory, be avoidable. Information about the underlying contributing factors is important to understand how to further refine prevention measures.

Our findings show that during the 2009 and 2014 episodes, the 15-64-year age group was particularly affected by mortality. Occupational exposures and the attitude of having to get on with life and work despite the heat may have contributed to the increased mortality in this age group. Preliminary evidence from a casecontrol study in Adelaide indicates that those who died during the hw2009 were much more likely to have had 
pre-existing heart disease and be lacking in social support compared with the general community control group. ${ }^{33}$ This evidence could be useful for the development of further preventive measures and focused health warnings.

There are some limitations to this study, particularly related to the separation of the hw2014 by a 9-day nonheatwave break. This may have rendered the intervention hw2014 as not entirely comparable with the 13-day continuing episode in 2009. Nevertheless, during both parts of the 2014 heatwaves, maximum temperatures of above $40^{\circ} \mathrm{C}$ were experienced over several days indicating risks to human health according to heat-health threshold investigations in Adelaide. ${ }^{13}{ }^{14}$ It is essential to continue evaluating future extreme heatwaves considering that the 2014 heatwaves are so far the only ones comparable in severity to the preintervention hw2009. The evaluation of the effectiveness of the HWS and interventions in Adelaide is therefore at an early stage, and this study has explored the effect of the intervention on health outcomes only. In order to make further progress and achieve further reductions, it will be necessary to assess how the services provided are receivedwhether they penetrate to the people most at need, whether their heightened awareness is transformed into likely beneficial behaviour changes and whether these improvements can be sustained.

Further studies requiring more detailed information about severity and subcategories of the critical health outcomes studied, coexisting diseases and other risk factors will enhance future evaluations.

\section{CONCLUSION}

Monitoring population health outcomes during extreme heat events is essential to inform the ongoing development of public health interventions. This comparison of extreme heat events in metropolitan Adelaide, 5 years apart, has provided initial evidence of improvements in health outcomes, possibly associated with the introduction of an HWS and public health intervention measures. Notwithstanding some differences between the two heatwaves, they represent the most significant recent heat events recorded for this population. Our findings showed there were marked reductions in renal and heat-related morbidity in 2014 compared with what was expected in relation to the hw2009, suggesting that awareness of warnings and advice during the heatwave may be a contributing factor. While direct heat-related illness dropped significantly, excess cases were still observed during the hw2014. Knowing that long-term prognosis can be poor following heat stress and heat stroke, particularly for older people, more emphasis should be placed on better communication with vulnerable groups to reduce heat exposure. While mortality is relatively low during heatwaves in Adelaide compared with other larger cities worldwide and in Australia, better outcomes could still be achieved. Targeted preventive measures may also have benefits for the wider population considering that everybody is potentially at risk. Evaluation of interventions is an iterative process and should be used continuously alongside fine tuning of the intervention measures using evidence-based research.

Acknowledgements The authors thank Dr David Simon, Director Scientific Services in SA Health for supporting this study.

Contributors MN has contributed to the conception and design of the study, has interpreted the data and has drafted the work and revised it critically for important intellectual content. GT has contributed to the design of the study, the acquisition, analysis and interpretation of the data and has revised the work for important intellectual content. $\mathrm{AH}, \mathrm{SW}$ and $\mathrm{YZ}$ have contributed to the interpretation of the data, the draft and revision of the work for important intellectual content. PB has contributed to the conception of the study and has revised the work critically for important intellectual content. All authors have provided final approval of the version published and are in agreement to be accountable for all aspects of the work in ensuring that questions related to the accuracy or integrity of any part of the work are appropriately investigated and resolved.

Funding This research received no specific grant from any funding agency in the public, commercial or not-for-profit sectors.

\section{Competing interests None declared.}

Provenance and peer review Not commissioned; externally peer reviewed.

Data sharing statement No additional data are available.

Open Access This is an Open Access article distributed in accordance with the Creative Commons Attribution Non Commercial (CC BY-NC 4.0) license, which permits others to distribute, remix, adapt, build upon this work noncommercially, and license their derivative works on different terms, provided the original work is properly cited and the use is non-commercial. See: http:// creativecommons.org/licenses/by-nc/4.0/

\section{REFERENCES}

1. Nitschke M, Tucker GR, Bi P. Morbidity and mortality during heatwaves in metropolitan Adelaide. Med J Aust 2007;187:662-5.

2. Nitschke M, Tucker GR, Hansen AL, et al. Impact of two recent extreme heat episodes on morbidity and mortality in Adelaide, South Australia: a case-series analysis. Environ Health 2011;10:42.

3. Palecki MA, Changnon SA, Kunkel KE. The nature and impacts of the July 1999 heat wave in the midwestern United States: learning from the lessons of 1995. Bull Am Meteorol Soc 2001;82:1353-67.

4. White-Newsome JL, Sanchez BN, Parker EA, et al. Assessing heat-adaptive behaviors among older, urban-dwelling adults. Maturitas 2011;70:85-91.

5. Kalkstein LS, Sheridan SC, Kalkstein AJ. Heat/health warning systems: development, implementation, and intervention activities. In: Ebi KL, ed. Biometeorology for adaptation to climate variability and change. Springer Science+Business Media, 2009:33-48.

6. Lowe D, Ebi KL, Forsberg B. Heatwave early warning systems and adaptation advice to reduce human health consequences of heatwaves. Int J Environ Res Public Health 2011;8:4623-48.

7. WMO (World Meteorological Organization), 2015: Heatwaves and health: guidance on warning-system development. WMO-No. 1142 , Geneva. http://www.who.int/globalchange/publications/WMO_WHO Heat_Health_Guidance_2015.pdf (accessed 26 Feb 2016).

8. Akompab DA, Bi P, Williams $\mathrm{S}$, et al. Engaging stakeholders in an adaptation process: governance and institutional arrangements in heat-health policy development in Adelaide, Australia. Mitig Adapt Strategies Glob Chang 2013;18:1001.

9. Toloo GS, Fitzgerald G, Aitken $P$, et al. Are heat warning systems effective? Environ Health 2013;12:27.

10. Boeckmann M, Rohn I. Is planned adaptation to heat reducing heat-related mortality and illness? A systematic review. BMC Public Health 2014;14:1112.

11. Fouillet A, Rey G, Wagner V, et al. Has the impact of heat waves on mortality changed in France since the European heat wave of summer 2003? A study of the 2006 heat wave. Int J Epidemiol 2008;37:309-17. 
12. South Australian State Emergency Service. Extreme Heat Plan. http://www.ses.sa.gov.au/site/community_safety/heatsafe/extreme_ heat_plan.jsp (accessed 26 Feb 2016).

13. Williams $S$, Nitschke $M$, Sullivan $T$, et al. Heat and health in Adelaide, South Australia: assessment of heat thresholds and temperature relationships. Sci Total Environ 2012;414:128-33.

14. Williams S, Nitschke M, Tucker G, et al. Extreme Heat Arrangements in South Australia: an assessment of trigger temperatures. Health Promot J Austr 2011;22:S21-7.

15. Red Cross. Telecross REDi Service. http://www.redcross.org.au/ telecross-redi.aspx (accessed 26 Feb 2016).

16. Hansen A, Bi P, Nitschke M, et al. Perceptions of heat-susceptibility in older persons: barriers to adaptation. Int $J$ Environ Res Public Health 2011;8:4714-28.

17. Nitschke $M$, Hansen $A L, B i P$, et al. Risk factors, health effects and behaviour in older people during extreme heat: a survey in South Australia. Int J Environ Res Public Health 2013;10: 6721-33.

18. Zhang Y, Nitschke M, Bi P. Risk factors for direct heat-related hospitalization during the 2009 Adelaide heatwave: a case crossover study. Sci Total Environ 2013;442:1-5.

19. Whitaker HJ, Hocine MN, Farrington CP. The methodology of self-controlled case series studies. Stat Methods Med Res 2009;18:7-26.

20. Whitaker HJ, Farrington CP, Spiessens B, et al. Tutorial in biostatistics: the self-controlled case series method. Stat Med 2006;25:1768-97.

21. Hansen MH, Hurwitz WN, Madow WG. Sample survey methods and theory, Vols I and II. New York: John Wiley \& Sons, 1953.

22. Bassil KL, Cole DC. Effectiveness of public health interventions in reducing morbidity and mortality during heat episodes: a structured review. Int J Environ Res Public Health 2010;7:991-01.

23. Semenza JC, McCullough JE, Flanders WD, et al. Excess hospital admissions during the July 1995 heat wave in Chicago. Am J Prev Med 1999;16:269-77.
24. Hansen AL, Bi P, Ryan P, et al. The effect of heat waves on hospital admissions for renal disease in a temperate city of Australia. Int $J$ Epidemiol 2008;37:1359-65.

25. Green R, Basu R, Malig B, et al. The effect of temperature on hospital admissions in nine California counties. Int J Public Health 2010;55:113-21.

26. Fletcher BA, Lin S, Fitzgerald EF, et al. Association of summer temperatures with hospital admissions for renal diseases in New York State: a case-crossover study. Am J Epidemiol 2012;175:907-16.

27. SA Health. Extreme Heat. http://www.sahealth.sa.gov.au/wps/wcm/ connect/public+content/sa+health+internet/protecting+public+health/ emergency+management/extreme+heat (accessed 26 Feb 2016).

28. Department of Human Services. January 2009 heatwave in Victoria: an assessment of health impacts. Melbourne, Victoria. 2009. https:// www2.health.vic.gov.au/getfile/?sc itemid=\%7B78C32CE8-A61947A6-8ED1-1C1D34566326\%7D\&title=January\%202009\% 20 Heatwave\%20in\%20Victoria\%3A\%20an\%20Assessment $\% 20$ of\% $20 \mathrm{Health} \% 20 \mathrm{Impacts}$ (accessed 26 Feb 2016).

29. Semenza JC, Rubin $\mathrm{CH}$, Falter $\mathrm{KH}$, et al. Heat-related deaths during the July 1995 heat wave in Chicago. N Engl J Med 1996;335:84-90.

30. Fouillet A, Rey G, Laurent F, et al. Excess mortality related to the August 2003 heat wave in France. Int Arch Occup Environ Health 2006;80:16-24.

31. Pascal M, Le Tertre A, Saoudi A. Quantification of the heat wave effect on mortality in nine French cities during summer. PLoS Curr 2012;4:RRN1307.

32. Hansen $\mathrm{A}, \mathrm{Bi} \mathrm{P}$, Pisaniello $\mathrm{D}$, et al. Heat-health behaviours of older people in two Australian states. Australas J Ageing 2015;34: E19-25.

33. Zhang Y, Nitschke M, Krackowizer A, et al. Abstracts of the 2011 Conference of the International Society of Environmental Epidemiology (ISEE). Abstract [O-053]. Research Triangle Park, NC: Environ Health Perspect. 